\title{
The Effects of Health Care Expenditures as a Percentage of GDP on Life Expectancies
}

\author{
Jacqueline Duba $^{1, *}$, Jonathan Berry ${ }^{1}$, Alan Fang $^{1} \&$ Matt Baughn ${ }^{1}$ \\ ${ }^{1}$ Clarkson University, USA \\ *Correspondence: Clarkson University, USA. E-mail: dubajm@clarkson.edu
}

Received: February 12, 2018 Accepted: April 2, 2018 Published: June 24, 2018

doi: 10.5296/rae.v10i2.12654 URL: https://doi.org/10.5296/rae.v10i2.12654

\begin{abstract}
The purpose of our research is to examine to see if there is a relationship between health care expenditures as a percentage of GDP and life expectancy for both females and males, consisting of 210 countries and regions over the period of 1995 to 2014. Along with health expenditure, we also use percent of the population in urban areas, primary completion rates, the amount of foreign aid received, agriculture value added, sanitation, and Carbon Dioxide (CO2) emissions per capita as our independent variables. The data that we collected indicates that there is a statistically significant link between life expectancies of both men and women and health care expenditures. During our research we ran our data through fixed effects regression model, this model is in use so that it would reduce the potential biases that we may have had during our experiment and test our hypothesis at the highest standard.
\end{abstract}

Keywords: Fixed Effects Model, Life Expectancies, Public Health Care Expenditures JEL Classification code: I10, I18 


\section{Introduction}

With the presence of vaccines, antibiotics, and technologically advanced medical equipment, humans today live much longer and disease-free lives than they did in the past. While several factors provide reasons for this increase in life expectancy, data seems to suggest an association between healthcare spending and people living longer lives. It would seem obvious that a country with a stable healthcare system, would increase the life expectancy of its citizens, but it is unknown how much healthcare contributes to a longer life. Furthermore, research on the relationship between healthcare spending and measures of health outcome, one of which is life expectancy, have provided inconclusive results. On the one hand, research by, among others, Crémieux, et al. (1999), Lichtenberg (2000), and Nixon and Ulmann (2006) report significant positive relationships between healthcare spending and life expectancy. On the other hand, Leu (1986), and Hitiris and Posnett (1992), and Barlow and Vissandjee (1999) fail to document a clear relationship between healthcare expenditures and measures of quality or length of life.

This paper revisits the question of the relationship between healthcare spending and life expectancy. Besides healthcare spending, our analysis controls for several economic, social, and environmental variables that potentially explain life expectancy. Using annual data for 210 countries over the period 1995 to 2010 and a fixed effects regression model, our results indicate a statistically significant positive relationship between healthcare spending and life expectancy. The results are robust even when we disentangle overall life expectancy into male and female measures of life expectancy. These findings have important policy implications as the results potentially guide world governments on possibly budgeting more for their countries' healthcare system. If healthcare plays a substantial role in determining life expectancy, it is the leader of a nation's best interest to invest in the healthcare system that is responsible for making its citizens live longer. The results of this analysis can also be helpful in showing the potential benefits of spending on research and development for new medical technology.

\section{Literature Review}

A recent study by Deshpande et al. (2014) compares health care expenditures to life expectancy using data for 181 countries. They used per capita expenditure on health as the measure of healthcare spending. The authors also controlled for the effects of per capita GDP, literacy rates, and density of physicians. A simple regression model between life expectancy and per capita health expenditure was estimated and an $R^{2}$ value of 0.66 was found, showing reasonably good measure of fit. In their regression results, they find that healthcare does not play much of a role in life expectancy in developing countries, but find that health care has a significant impact on increasing the life expectancy of developed nations. In fact, for some developing countries, they find negative relationships between healthcare spending and life expectancy. They hypothesize that this is due to the quality of health care expenditure. 


\section{Mll Macrothink}

Research in Applied Economics

ISSN 1948-5433

2018, Vol. 10, No. 2

Countries that tended to spend more efficiently on healthcare tended to have higher life expectancy. Deshpande et al. (2014) also found that in developing countries, the density of physicians was the most statistically significant variable, suggesting that in developing countries, access to doctors can be of greater value than expenditure on health care.

In another recent study, Jaba et al. (2014) examine the relationship between the inputs and outputs of the healthcare system. For the study, the input is considered the healthcare expenditure, and the output is life expectancy. It was done using a panel regression analysis across 175 countries for the period 1995 to 2010. The primary variable was the total health expenditure (sum of government and private expenditures). Their results show a significant positive relationship between healthcare expenditure and the life expectancy at birth, with the results more significant for developed countries. The study also finds that a decrease in infant mortality due to advances in medicine to be the cause of the increase in life expectancy at birth.

Another article by Nixon and Ullmann (2006) aims to show the relationship between health care expenditure and health outcomes. Data is collected from fifteen members of the European Union from 1980 to 1995, so the study only focused on advanced countries. Measures for life expectancy for both males and females and infant mortality were analyzed while taking into account healthcare expenditure as a percentage of GDP. Interestingly, through panel regression, this study finds that there is a positive relationship between healthcare expenditure and infant survival rates. This relationship is also statistically significant. There is only a marginal relationship between health care spending and life expectancy, however.

Besides healthcare expenditures, the literature abounds with other variables that determine life expectancy. While socioeconomic factors are frequently purported to explain life expectancy (see, e.g., Wilkinson, 1992; Yavari and Mehrnoosh, 2006; Iacobuta and Cuza, 2012), recent empirical studies have identified environmental factors as possible determinants of life expectancy. A study conducted by Pope et al. (2009) looked at the effect of fine-particulate air pollution on the life expectancy of the United States. They looked at 211 counties in the 51 United States metropolitan areas during the years of the 1970s to the early 2000s. Their dataset included data life expectancy, demographic characteristics, and socioeconomic statuses such as work experience, income, and education. They found from their investigation that a reduction in the exposure to fine particulate air pollution significantly increases the mean life expectancy throughout the United States. In a related study by Chen et al. (2013) documented evidence that higher pollution rates decrease the life expectancy of people. The paper looked at the effect that China's Huai River policy had on pollution and life health outcomes. The authors collected data on 90 cities between 1981 and 2000 on pollution concentration. They concluded that pollution in northern China was 55\% higher than in the south and that life expectancy was an astonishing five and a half years less. These studies suggest that besides traditional socioeconomic drivers of life expectancy, it is necessary to control for the effect of environmental factors when attempting to estimate the relationship between healthcare spending and life expectancy. 
Selck and Deckarm (2015) argued that one weakness with macro-quantitative studies on the determinants of life expectancy in economics, medicine, and public health, and political science is that they do not consider the impact that improved sanitation has on the average length of life. Using cross-sectional data for 2012 for some countries, and the method of ordinary least squares (OLS), the authors including sanitation in their model increases the explained variance of life expectancy by as much as 11 percentage points while controlling for income, democracy, and other determinants of life expectancy. In a related study done by Hertz et al. (1994) found a strong correlation between sanitation and infant and maternal mortality. Other variables such as food availability and water were also found to be significant. They used data from the United Nations for 35 countries. They also reported that literacy and growth of the labor force had little to do with determining life expectancy or mortality rates.

The current literature shows that healthcare expenditure has some effect on life expectancy, after controlling for a number of other variables. We, however, find a gap in the literature: relatively few studies take into account the broad range of countries including developing and developed countries, while also considering environmental factors that influence life expectancy. While our primary goal is to show the effect of healthcare expenditure on life expectancy, the paper also contributes to the literature by controlling for the effect of other economic and ecological factors that affect life expectancy.

\section{Data and Methodology}

The explanatory variable used in this paper is the life expectancy at birth. The World Bank defines life expectancy at birth as "the number of years a newborn infant would live if prevailing patterns of mortality at the time of its birth were to stay the same throughout its life." Life expectancy data are collected and displayed as a weighted average and are good indicators of the general health of a country, as well as a frequently used comparison of "socioeconomic development across countries" (The World Bank, 2016).

The choice of the independent variables in this paper is by the literature, notably the ones cited in the literature review. All the data on these variables come from the World Bank. Our primary independent variable is healthcare expenditures as a percentage of GDP. By using expenditures as a percentage of GDP, we are controlling for the economic size of countries. We expect a positive correlation between healthcare spending and life expectancy, or that the countries that are spending more on health care will have longer life expectancy.

The second independent variable is the percentage of the population that lives in urban areas. Urbanization is one measure of the level of development. As economies move from agriculture to industrial and service economies, the percent of the population living in urban areas will increase, as more jobs become available in those areas. Urban areas, in general, have better access to healthcare options. Therefore we expect that as more of the population moves to urban areas, there will also be a rise in life expectancy.

Our model also includes primary school completion rates as a proxy for a country's level of 


\section{Ml Macrothink}

Research in Applied Economics

ISSN 1948-5433

2018, Vol. 10, No. 2

human capital. We expect that a more educated population has more information about health and sanitation, and can make more informed decisions about their health. We believe that with a percentage of primary school completion will be a positive correlation with life expectancy.

We include foreign development assistance and aid received, measured as the net receipts of loans and grants provided to countries to "promote economic development and welfare in countries" (The World Bank, 2016). This data is a measure of the net inflows and outflows of aid and should be a good measure of the growth of a country over time. For this variable, we predict a negative correlation with life expectancy, as countries that receive more aid are developing countries and therefore have a lower life expectancy.

Furthermore, the model includes agriculture value added, measured as a percentage of GDP. Agriculture value added is the sum of outputs less the value of the inputs of all agriculture in an economy. This includes fishing, hunting, timber production, as well as farming. Our basis for using this variable is to examine any correlation between life expectancy and a change in agriculture in an economy as a percent of GDP.

Another independent variable we consider is the percent of the population that has access to improved sanitation. Improved sanitation is important to societies, as it decreases the incidence of disease. A positive correlation between sanitation and life expectancy at birth is to be expected. The model also accounts for the amount of carbon dioxide (CO2) emissions per capita, measured in metric tons. We chose this variable as a measure of pollution produced by a given population. The association with higher pollution levels with the increase in health issues, and therefore, we expect a negative correlation between $\mathrm{CO} 2$ levels and life expectancy. By using a per capita measurement, we control for size population size of the country.

To control for the differences in development between countries, we included a variable that categorizes countries as developed versus developing, based the classification of the United Nations. We expected that developed countries would have a greater significance in the correlation between life expectancy and health expenditures than developing countries. Hence we expect a positive sign on the coefficient of this variable. Our model controls for unobservable time-invariant country-specific effects, as well as time-varying fixed effects.

This analysis uses data from 210 countries and territories. Some territories, while not countries in and of themselves, are sovereign entities. The data collected were for the years 1995 to 2014. The sample period is on the availability of data. Table 1 provides descriptive statistics of the data. 


\begin{tabular}{lccccc}
\hline Variable Name & $\begin{array}{c}\text { Number } \\
\text { Observations }\end{array}$ & $\begin{array}{c}\text { of } \\
\text { Value }\end{array}$ & $\begin{array}{c}\text { Maximum } \\
\text { Value }\end{array}$ & $\begin{array}{c}\text { Mean } \\
\text { Value }\end{array}$ & $\begin{array}{c}\text { Standard } \\
\text { Deviation }\end{array}$ \\
\hline Health Expenditure (\% GDP) & 3755 & 0.368 & 21.880 & 6.179 & 2.507 \\
Male Life Expectancy (Years) & 3952 & 28.095 & 81.6 & 66.016 & 9.233 \\
Female Life Expectancy (Years) & 3592 & 35.351 & 86.9 & 70.789 & 10.423 \\
Urbanization Rate & 4177 & 7.211 & 100 & 55.821 & 24.742 \\
Primary School Completion Rate & 2319 & 13.933 & 185.297 & 85.952 & 21.901 \\
Foreign Aid Received (\$ billion) & 3170 & -9.590 & 22.06 & 5.07 & 1.64 \\
Agriculture Share (\% GDP) & 3485 & 0.000 & 62.383 & 14.561 & 13.437 \\
Access to Sanitation (\% Pop.) & 3878 & 3.000 & 100.000 & 69.523 & 30.301 \\
$\mathrm{C}_{2}$ Emissions Per Capita & 3942 & 0.002 & 70.984 & 4.883 & 6.693 \\
\hline
\end{tabular}

Following this discussion, our baseline econometric model is:

$$
\begin{aligned}
& L E_{i t} \\
& =\beta_{1}+\beta_{2} \text { Health }_{i t}+\delta_{i}+\psi_{i}+u_{i t}
\end{aligned}
$$

where $L E_{i t}$ is life expectancy in country $i$ in year $t$, Health $h_{i t}$ denotes healthcare spending in country $i$ in year $t, \delta_{i}$ denotes time-invariant country effects, $\psi_{i}$ the unobservable time-varying effects, $u_{i t}$ denotes the idiosyncratic error term, and $\beta_{1}$ and $\beta_{2}$ are parameters to be estimated. Even though equation (1) includes $\delta_{i}$ - time-invariant country effects, and $\psi_{i}$ - the unobservable time-varying effects to decrease the severity of unobservable factors that affect life expectancy, the model still likely suffers from omitted variable bias as key observable variables that affect life expectancy have been omitted. To control for the other variables that potentially affect life expectancy discussed above, we also estimate the model:

$$
\begin{aligned}
\text { LE }_{i t}=\beta_{1}+ & \beta_{2} \text { Health }_{i t}+\text { Education }_{i t}+\text { Urban }_{i t}+\text { Aid }_{i t}+\text { Agriculture }_{i t} \\
& + \text { Sanitation }_{i t}+\text { CO2 }_{i t}+\text { Developed }_{i t}+\delta_{i}+\psi_{i} \\
& +u_{i t}
\end{aligned}
$$

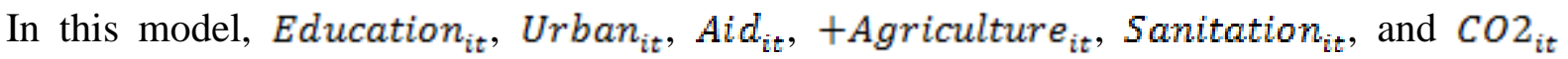
respectively denote the primary school completion rate, urbanization rate, net official development assistance and aid received, agriculture share of GDP, access to improved sanitation, carbion dioxide emissions, of country $i$ in year $t$. Developed $d_{i t}$ is a dummy variable that takes a value of 1 for developed countries, and 0 for developing countries. All the other variables remain as previously defined.

\section{Estimation and Results}

\subsection{Estimation}

Our dataset is considered panel data, which is the combination of time series data and cross-sectional data; which ultimately means that our results came from multiple time periods 


\section{Macrothink}

for various countries. Due to things such as cultural factors, the difference in business climate, and natural amenities which vary across countries but are not observable, as well as factors that change over time, such as national policies, government regulations, and international agreements, a fixed effects regression is the appropriate estimation methodology. If we fail to account for this so-called individual heterogeneity, by estimating our models using the method of ordinary least squares (OLS), our results will be biased. Therefore, the main reason people use fixed effects methods in is its ability to control all the characteristics of the individuals gathered, this then allows them to eliminate all the potentially significant biases.

An alternative model to fixed effects is called the random effects model. The idea underlying this model, unlike the fixed effects model, is that it assumes that the variation across entities is random and uncorrelated with the explanatory variables in the model. In general, a test called the Hausman specification test is often used to test which model - fixed effects or random effects - is appropriate for the empirical study. For completeness, we will present the results for the OLS, fixed effects, and random effects models.

\subsection{Results}

\subsubsection{Graphical Analysis}

As a preliminary analysis, Figure 1 presents a simple scatter plot of healthcare expenditures against life expectancy for all the countries in our sample. Panel A looks at average life expectancy, while in panels $\mathrm{B}$ and $\mathrm{C}$, we inspect whether the relationship seems to vary between males and females. Figure 2 presents the same plots for advanced economies, and Figure 3 for developing countries.

All three figures suggest a strong positive relationship between healthcare spending and life expectancy. Figure 1 shows that the positive relationship remains strong regardless of gender. Figures 2 and 3 show that the relationship varies considerably between developed and developing economies. For developed countries (Figure 2), the correlation between healthcare expenditures and life expectancy is still strong and positive for both males and females. On the other hand, for developing countries, the relationship appears weak. For males, Figure 3C shows that the relationship is almost zero. Caution, however, must be exercised as these plots as they only show a correlation between the two variables without controlling for other factors that affect life expectancy across countries. 

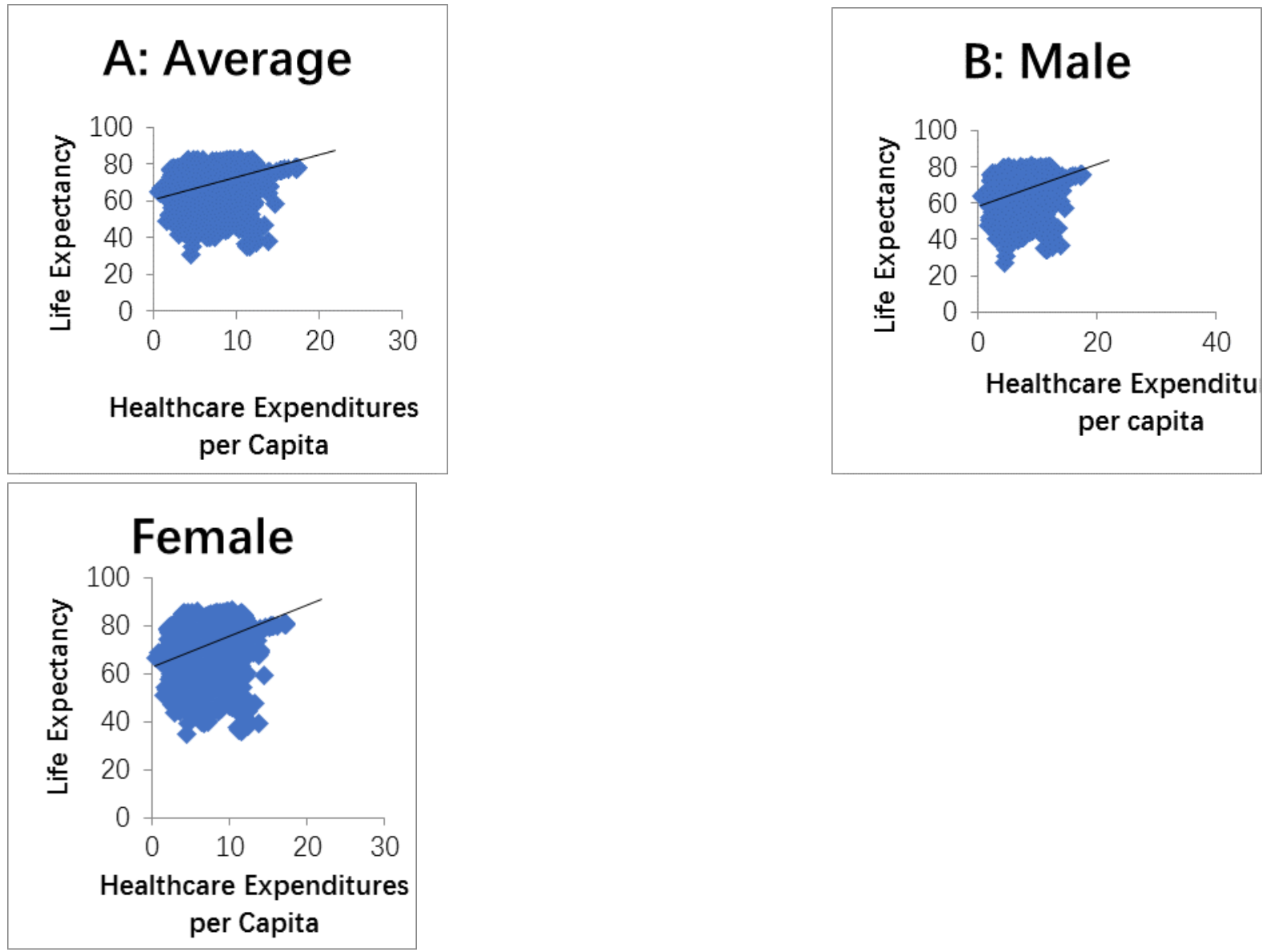

Figure 1. Healthcare Expenditures versus Life Expectancy
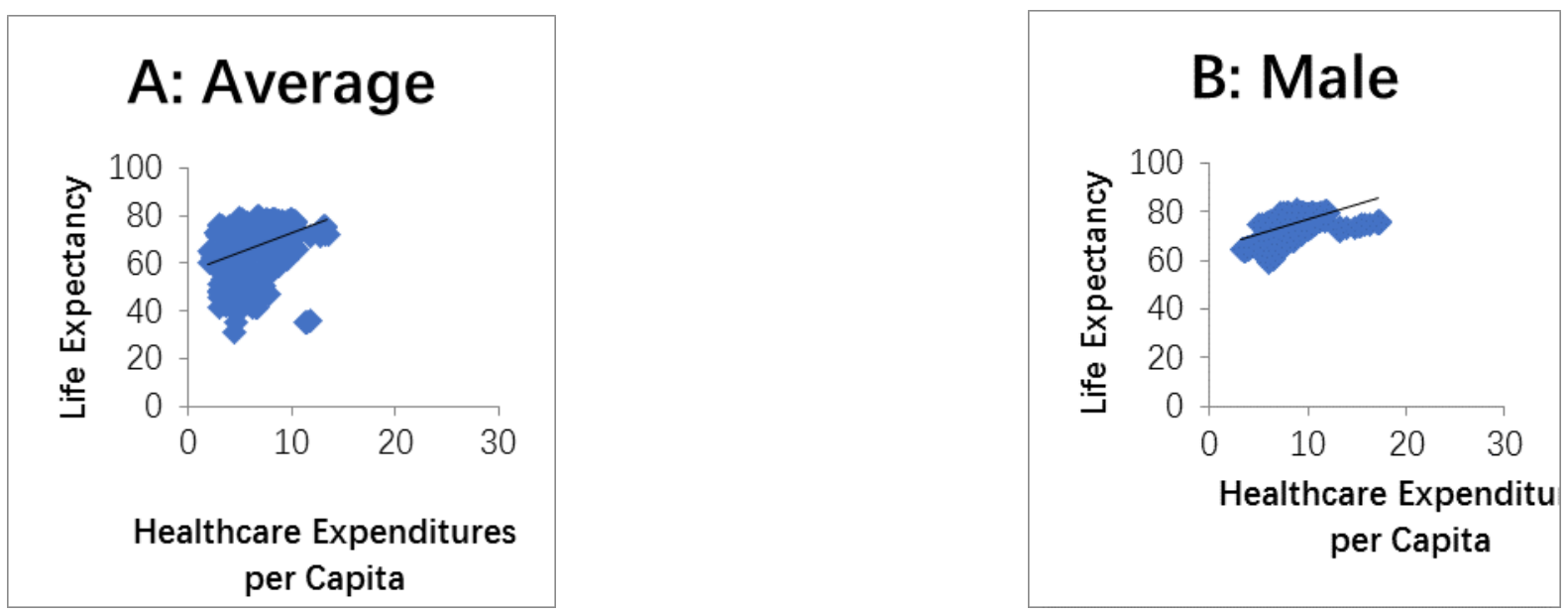


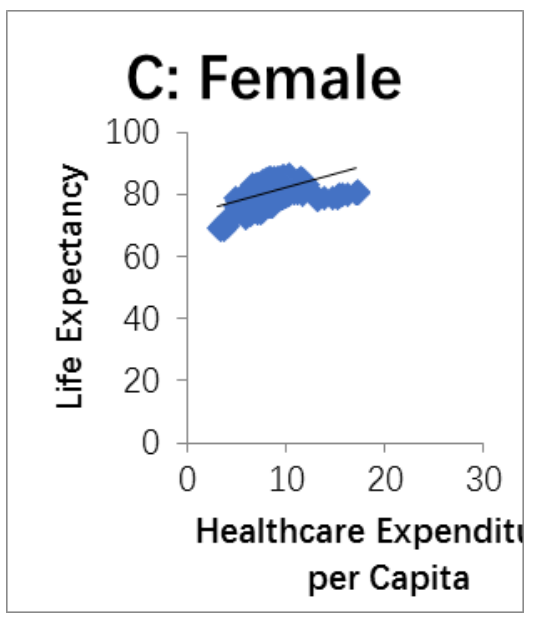

Figure 2. Healthcare Expenditures versus Life Expectancy: Developed Countries
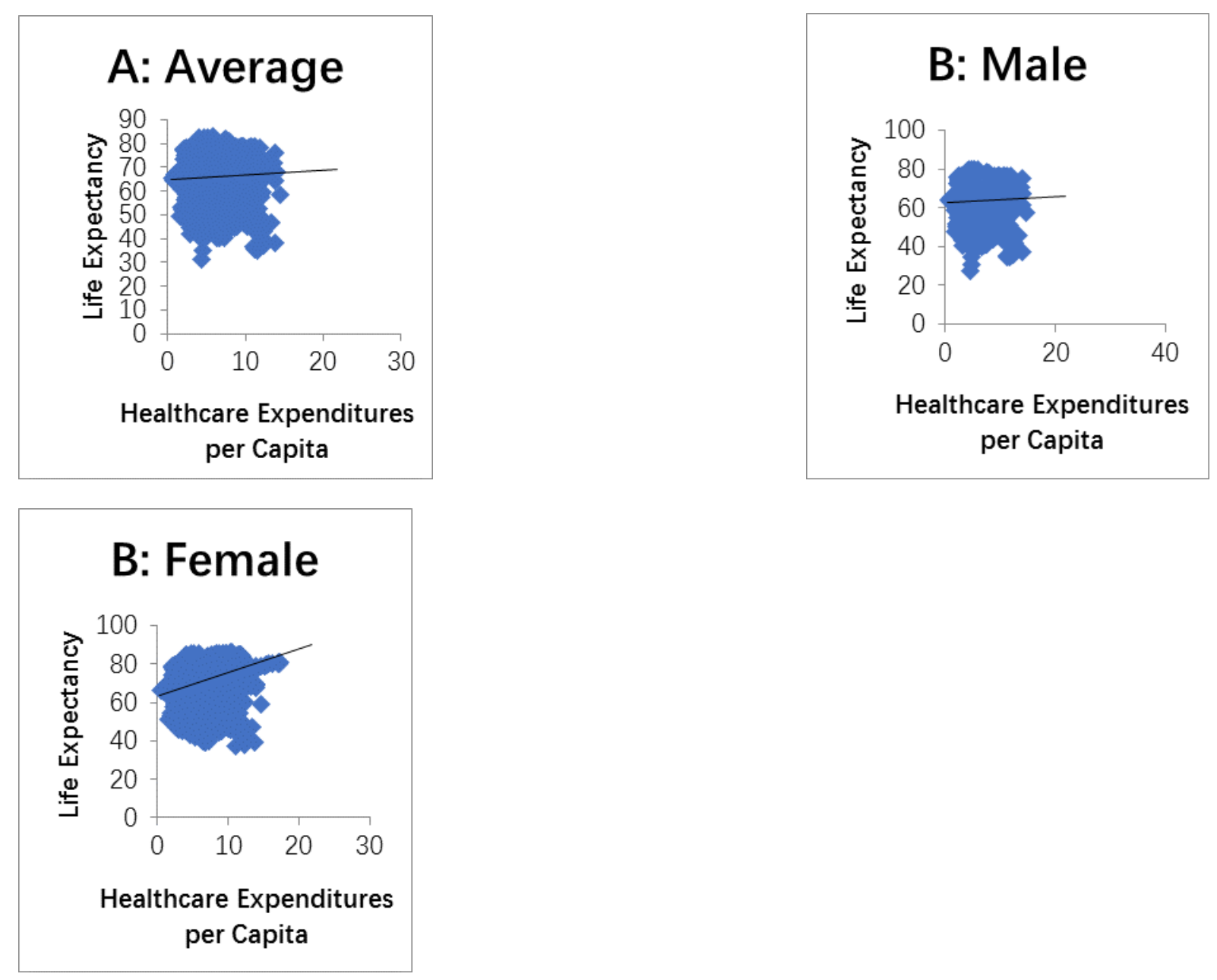

Figure 3: Healthcare Expenditures versus Life Expectancy: Developing Countries 


\subsubsection{Regression Results}

In this section, we present results of estimating equations (1) and (2). All results in this paper are estimated using STATA. Table 2 presents OLS, fixed effects, and random effects estimates of the benchmark model in equation (1). In Table 2A, we present results of a regression of average life expectancy on healthcare expenditures; $2 \mathrm{~B}$, a regression of male life expectancy on healthcare expenditures; and $2 \mathrm{C}$, a model of female life expectancy on healthcare expenditures.

Before proceeding to discuss the results presented in Table 2, it is important to note that while we present OLS, fixed effects, and random effects estimates, and discuss their estimated coefficients, our preferred model is the fixed effects model. As noted, OLS estimation is biased because it does not control for unobservable time and individual factors that affect life expectancy within and between countries. As further discussed above, a Hausman specification test is usually used to test whether the fixed effects or random effects model is appropriate for the empirical study. We carried out this test for our analysis and found the test statistic is $\chi^{2}=31.12(p-$ value $=0.0003)$. This provides significant evidence in favor of the fixed effects model and against the random effects model.

Several observations are from tables 1A to 1C. First, regardless of the model, healthcare spending appears to have a positive relationship with life expectancy. The relationship is strong, and highly statistically significant (at the $1 \%$ level of significance). Second, the fixed effects estimates are smaller than the OLS and random effects estimates. Third, the relationship is larger for males (estimate of 0.1350, Table 2B) than for females (estimate of 0.0760, Table 2C). As expected, the estimate of the relationship between healthcare spending an average life expectancy (0.1055) lies between the estimate for male and the estimate for female life expectancy. Fourth, healthcare spending explains as much as $62 \%$ of the variation in male life expectancy, 58\% of female life expectancy, and $61 \%$ of average overall life expectancy. Taken together, the results in Table 2 suggest a strong positive, statistically significant, and economically significant relationship between healthcare expenditures and life expectancy.

Table 2A. Effect of Healthcare Spending on Average Life Expectancy

\begin{tabular}{lccc}
\hline Variable & OLS & Fixed Effects & Random Effects \\
\hline Constant & $60.5818^{* * *}$ & $70.4229 * * *$ & $70.3313^{* * *}$ \\
& $(0.4240)$ & $(0.2115)$ & $(0.6865)$ \\
Health & $1.2328 * * *$ & $0.1055^{* * *}$ & $0.1152^{* * *}$ \\
& $(0.0646)$ & $(0.0267)$ & $(0.0266)$ \\
$R-$ squared & 0.0916 & 0.6056 & 0.0046 \\
\hline
\end{tabular}


Table 2B. Effect of Healthcare Spending on Male Life Expectancy

\begin{tabular}{lccc}
\hline Variable & OLS & Fixed Effects & Random Effects \\
\hline Constant & $58.6765^{* * *}$ & $67.8578 * * *$ & $67.7728 * * *$ \\
& $(0.4006)$ & $(0.2115)$ & $(0.6511)$ \\
Health & $1.1557 * * *$ & $0.1350 * * *$ & $0.1442 * * *$ \\
& $(0.0611)$ & $(0.0261)$ & $(0.0260)$ \\
$R-$ squared & 0.0902 & 0.6210 & 0.0113 \\
\hline
\end{tabular}

Table 2C. Effect of Healthcare Spending on Female Life Expectancy

\begin{tabular}{lccc}
\hline Variable & OLS & Fixed Effects & Random Effects \\
\hline Constant & $62.4870 * * *$ & $72.9879 * * *$ & $72.888 * * *$ \\
& $(0.4529)$ & $(0.2230)$ & $(0.7332)$ \\
Health & $1.3099 * * *$ & $0.0760 * * *$ & $0.1152 * * *$ \\
& $(0.0691)$ & $(0.0281)$ & $(0.0281)$ \\
$R-$ squared & 0.0916 & 0.5757 & 0.0004 \\
\hline
\end{tabular}

Notes: Numbers in parentheses are standard errors. $* * *$ indicates significance at $1 \%$ level. For the fixed effects model, the $R$-squared is the within $R$-squared, while for the random effects model, the $R$-squared is the between $R$-squared.

While the fixed effects model controls for unobservable time and individual effects, model (1) omits important observable factors purported in the literature to explain differences in life expectancy across countries. Accordingly, Table 3 presents OLS, fixed effects, and random effects estimates of the model (2). We will focus our discussion primarily on the estimates on the fixed effects model, and when necessary, make comparisons with the estimates of the OLS and random effects models.

Looking at the fixed effects estimate of the coefficient on healthcare expenditures in Table $3 \mathrm{~A}$ (0.1285) shows a positive relationship between healthcare spending and average life expectancy. The relationship is also statistically significant (standard error $=0.0387$ ). Comparing the fixed effects estimates to the OLS estimates, the bias in OLS is apparent. The coefficient on healthcare expenditures is negative and significant, which is contrary to expectations. The random effects estimates, however, are similar to the fixed effects estimates regarding magnitude, sign, and statistical significance. This result of a positive relationship supports the findings of Jaba et al. (2014), Aísa et al. (2014), and Kim and Lane (2013). 


\section{$\Lambda$ Macrothink}

Table 3A. Effect of Healthcare Spending on Average Life Expectancy: Additional Controls

\begin{tabular}{lccc}
\hline Variable & OLS & Fixed Effects & Random Effects \\
\hline Constant & $37.9754 * * *$ & $50.2375^{* * *}$ & $45.6748^{* * *}$ \\
Health & $(1.9416)$ & $(2.0071)$ & $(1.8943)$ \\
& $-0.1177 * *$ & $0.1285^{* * *}$ & $0.1332^{* * *}$ \\
Education & $(0.0599)$ & $(0.0387)$ & $(0.0394)$ \\
& $0.1053^{* * *}$ & $0.0479^{* * *}$ & $0.0531^{* * *}$ \\
Urban & $(0.0072)$ & $(0.0048)$ & $(0.0048)$ \\
& $0.0784^{* * *}$ & $0.0623^{* * *}$ & $0.0836^{* * *}$ \\
Aid & $(0.0073)$ & $(0.0227)$ & $(0.0159)$ \\
& $0.3587 * * *$ & $0.4295^{* * *}$ & $0.3730^{* * *}$ \\
Agriculture & $(0.0894)$ & $(0.0710)$ & $(0.0712)$ \\
& -0.0556 & $0.3982^{*}$ & -0.0795 \\
Sanitation & $(0.2158)$ & $(0.2270)$ & $(0.2149)$ \\
& $0.1571 * * *$ & $0.0209^{*}$ & $0.0961^{* * *}$ \\
CO2 & $(0.0065)$ & $(0.0119)$ & $(0.0105)$ \\
& $-0.1224 * * *$ & -0.0546 & 0.0117 \\
Developed & $(0.0416)$ & $(0.0454)$ & $(0.0398)$ \\
& -0.0767 & -0.6119 & 0.8880 \\
$R-$ squared & $(0.4678)$ & $(1.0432)$ & $(1.0432)$ \\
& 0.7352 & 0.6592 & 0.6973
\end{tabular}

Notes: Numbers in parentheses are standard errors. ${ }^{*} *, * *$, and $*$ respectively indicate significance at $1 \%$ level. For the fixed effects model, the $R$-squared is the within $R$-squared, while for the random effects model, the $R$-squared is the between $R$-squared.

Turning to the coefficient on the other variables, education exhibits a positive association with life expectancy. This is not surprising considering the extensive literature that has produced similar findings. Cutler and Lleras-Muney (2006) provide explanations for this positive (causal) relationship. They found significant associations between educational attainment and several health risk factors. In particular, they found that more educated individuals were 11 percentage points less likely to smoke, drank seven fewer days of 5 or more drinks in a year, were five percentage points less likely to be overweight, and tended to use illicit drugs 0.6 percentage points less. They also reported that more educated individuals were seven percentage points more likely to exercise and receive preventive care. More educated women were ten percentage points more likely to receive mammograms, ten percentage points more likely to request pap smears, and 2.4 percentage points more likely to obtain colonoscopies. Cutler and Lleras-Muney (2006) further show that the more educated tended to use seat belts by 12 percentage points relative to an average of $68 \%$, and were 10.8 percentage points more likely to install smoke detectors in their homes. These same factors possibly explain the positive relationship between education and average life expectancy we report in Table $3 \mathrm{~A}$. 


\section{Mll Macrothink}

Research in Applied Economics

ISSN 1948-5433

2018, Vol. 10, No. 2

A positive relation between urbanization and life expectancy is found in Table 3A. This is consistent with McDade and Adair (2001) who argue that improvements in infrastructure that result from urbanization, such as access to health services, more educational opportunities, improved sanitation, and clean water, improve health outcomes. Tatem et al. (2013) found that urbanization is correlated with reductions in malaria transmission, while Kohler (2013) argued that increased urbanization, particularly in developing countries, increases communications technology, which provides individuals with access to information needed to help with disease prevention. Our significantly positive coefficient on urbanization supports these arguments.

Our results also show that foreign aid and improved sanitation both have significant relationships with life expectancy. Following the argument of McDade and Adair (2001), among others, the positive sign on the coefficient on sanitation is not surprising. As well, that aid and health outcomes, including life expectancy, have a positive relationship has been documented by Bendavid and Bhattacharya (2016), and Cuberes and Tsui (2017). Bendavid and Bhattacharya (2016) argued that this positive relationship should be expected, especially for the years considered in our paper, as in recent years, the majority of aid to developing countries has generally been earmarked to finance highly effective technologies such as antiretroviral therapy, insecticidal-treated bed nets, and new vaccines, all of which should increase life expectancy.

Our results also show that $\mathrm{CO} 2$ emissions and the level of development do not have significant impacts on average life expectancy. These findings are surprising, given that some studies have found these variables to be significant predictors of life expectancy (see, e.g., Pope et al., 2009; and Chen et al., 2013).

To examine whether health expenditures have different effects on male and female life expectancy, we re-estimate our models with male and female life expectancy as the dependent variables. These results are found in Tables 3B and 3C. As before, we focus on the fixed effects estimates, following the results of Hausman specification tests. The results are generally consistent with those shown in Tables 2 and Table 3A. That is, we find a positive relationship between healthcare expenditures and life expectancy for males and females. As in Tables $2 \mathrm{~B}$ and $2 \mathrm{C}$, the results show that the impact of healthcare spending is larger for males (estimate of 0.1416, Table 3B) than for females (estimate of 0.1154 , Table 3C).

The estimates of the control variables are consistent with those reported in Table 3A: education, urbanization, and foreign aid all display positive and significant coefficients, while as before $\mathrm{CO} 2$ emissions and the indicator variable for the level of development are statistically insignificant. One noteworthy finding is that agriculture is an insignificant predictor of male life expectancy, but a highly significant predictor of female life expectancy, suggesting that female life expectancy drives the significantly positive coefficient on average life expectancy.

Taken together, the results of this paper indicate a significant positive relationship between healthcare expenditures and life expectancy. The findings are robust to the inclusion of additional variables that have been shown to impact on life expectancy. The results remain stable even when we separate average life expectancy into male and female life expectancy. 


\section{Mll Macrothink}

Table 3B. Effect of Healthcare Spending on Male Life Expectancy: Additional Controls

\begin{tabular}{lccc}
\hline Variable & OLS & Fixed Effects & Random Effects \\
\hline Constant & $39.8981^{* * *}$ & $49.0832 * * *$ & $45.1912 * * *$ \\
Health & $(1.9607)$ & $(1.9336)$ & $(1.8294)$ \\
& $-0.1259 * *$ & $0.1416^{* * *}$ & $0.1436 * * *$ \\
Education & $(0.0605)$ & $(0.0373)$ & $(0.0377)$ \\
& $0.1007 * * *$ & $0.0489^{* * *}$ & $0.0532 * * *$ \\
Urban & $(0.0073)$ & $(0.0046)$ & $(0.0047)$ \\
& $0.0716^{* * *}$ & $0.0410^{*}$ & $0.0705^{* * *}$ \\
Aid & $(0.0074)$ & $(0.0219)$ & $(0.0156)$ \\
& $0.3257 * * *$ & $0.4247 * * *$ & $0.3721^{* * *}$ \\
Agriculture & $(0.0902)$ & $(0.0684)$ & $(0.0683)$ \\
& -0.4725 & 0.3074 & -0.1568 \\
Sanitation & $(0.2179)$ & $(0.2187)$ & $(0.2069)$ \\
& $0.1304 * * *$ & $0.0216^{*}$ & $0.0819 * * *$ \\
CO2 & $(0.0066)$ & $(0.0124)$ & $(0.0102)$ \\
& $-0.1837 * * *$ & -0.0703 & -0.0037 \\
Developed & $(0.0420)$ & $(0.0438)$ & $(0.0386)$ \\
& -0.6952 & -1.0931 & 0.1039 \\
$R-$ squared & $(0.4725)$ & $(1.3875)$ & $(1.0247)$ \\
\end{tabular}

Notes: Numbers in parentheses are standard errors. $*^{* *},{ }^{*}$, and $*$ respectively indicate significance at $1 \%$ level. For the fixed effects model, the $R$-squared is the within $R$-squared, while for the random effects model, the $R$-squared is the between $R$-squared.

Table 3C. Effect of Healthcare Spending on Female Life Expectancy: Additional Controls

\begin{tabular}{lccc}
\hline Variable & OLS & Fixed Effects & Random Effects \\
\hline Constant & $36.0528^{* * *}$ & $51.3918^{* * * *}$ & $46.2054^{* * *}$ \\
& $(2.0167)$ & $(2.1318)$ & $(2.0133)$ \\
Health & $-0.1096^{*}$ & $0.1154^{* * *}$ & $0.1234^{* * *}$ \\
& $(0.0622)$ & $(0.0411)$ & $(0.0420)$ \\
Education & $0.1099^{* * *}$ & $0.0470^{* * *}$ & $0.0531^{* * *}$ \\
& $(0.0074)$ & $(0.0051)$ & $(0.0052)$ \\
Urban & $0.0850^{* * *}$ & $0.0836^{* * *}$ & $0.0963 * * *$ \\
& $(0.0077)$ & $(0.0242)$ & $(0.0167)$ \\
Aid & $0.3917 * * *$ & $0.4344^{* * *}$ & $0.3765^{* * *}$ \\
& $(0.0928)$ & $(0.0754)$ & $(0.0759)$ \\
Agriculture & 0.3612 & $0.4891 * *$ & 0.0109 \\
& $(0.2242)$ & $(0.2411)$ & $(0.2287)$ \\
Sanitation & $0.1837 * * *$ & 0.0201 & $0.1091 * * *$ \\
& $(0.0069)$ & $(0.0137)$ & $(0.0111)$ \\
CO2 & $-0.0612^{* * *}$ & -0.0388 & 0.0260 \\
& $(0.0432)$ & $(0.0482)$ & $(0.0422)$ \\
Developed & 0.5416 & -1.1306 & 1.6804 \\
& $(0.4859)$ & $(1.5297)$ & $(1.0998)$ \\
$R-$ squared & 0.6805 & 0.6706 & 0.7173 \\
\hline
\end{tabular}

Notes: Numbers in parentheses are standard errors. $* * *, * *$, and $*$ respectively indicate significance at $1 \%$ level. For the fixed effects model, the $R$-squared is the within $R$-squared, while for the random effects model, the $R$-squared is the between $R$-squared. 


\section{Conclusion}

Healthcare has been a hotly debated topic in recent years, and it is critically important to be able to measure its effects on societies. Our research sought to build on the research of others and to find variables that other authors may not have included. We also tried to control for differences in economical sizes by using percentages, and if where we could not use percentages, per capita data. Also, by using panel data, we control for variation in time and variables that cannot easily be measured. Within these boundaries, we have determined that there is a statistically significant increase in life expectancies for both men and women, with an increase in health expenditures as a percentage of GDP, holding our other variables constant.

From among our independent variables, five of the seven also had statistically significant effects on life expectancies. The surprising results were the effect of our qualitative variable on our model. We would assume that holding all other variables constant, that being a developed country would have a positive correlation on life expectancy, but we found the opposite to be true for both sexes, although the data was statistically insignificant for our research. Despite that, it makes for a compelling topic for future research. More work needs to be done to determine whether or not there actually is a correlation between economic development and life expectancy.

With the collection of more data, we see an opening to gain further insight by looking at variables related to the consumption of various goods. We did a search for variables on tobacco and alcohol usage as well as obesity, to further explain why some countries may have greater health care expenditures account for a greater percentage of their GDP. However, the available data is inadequate, and therefore not useful for our purposes at this time.

\section{References}

Agriculture, value added (\% of GDP). (2016). The World Bank Group.

Allison, P. D. (2005). Introduction to Fixed Effects Methods. In P. D. Allison, Fixed Effects Regression Methods for Longitudinal Data Using SAS (pp. 1-8). SAS Institute.

CO2 emissions (metric tons per capita). (2016). The World Bank Group.

Country Classification Data sources, country classifications and aggregation methodology. (2012). World Economic Situation and Prospects 2012.

Chen, Y., Ebenstein, A., Greenstone, M., \& Li, H. (2013). Evidence on the impact of sustained exposure to air pollution on life expectancy from China's Huai River policy. Proceedings of the National Academy of Sciences of the United States of America, 12936-12941. https://doi.org/10.2139/ssrn.2291154

Deshpande, N., Kumar, A., \& Ramaswami, R. (2014). The Effect of National Healthcare Expenditure on Life Expectancy. Georgia Tech Library. Retrieved from http://www.library.gatech.edu 


\section{Macrothink}

Grosse, R. N., \& Perry, B. H. (1982). Correlates of life expectancy in less developed countries. Health Policy and Education, 275-304. https://doi.org/10.1016/0165-2281(82)90014-5

Health expenditure, total (\% of GDP). (2016). The World Bank Group.

Hertz, E., Herbert, J. R., \& Landon, J. (1994). Social and environmental factors and life expectancy, infant mortality, and maternal mortality rates: Results of a cross-national comparison. Social Science \& $\quad$ Medicine, $105-114$. https://doi.org/10.1016/0277-9536(94)90170-8

Improved sanitation facilities (\% of population with access). (2016). The World Bank Group.

Jaba, E., Balan, C. B., \& Robu, I.-B. (2014). The relationship between life expectancy at birth and health. Procedia Economics and Finance. 15, 108-114. https://doi.org/10.1016/S2212-5671(14)00454-7

Life expectancy at birth, female (years). (2016). The World Bank Group.

Life expectancy at birth, male (years). (2016). The World Bank Group.

Net official development assistance and official aid received (current US\$). (2016). The World Bank Group.

Nixon, J., \& Ulmann, P. (2006). The relationship between health care expenditure and health outcomes. Evidence and caveats for a causal link. PubMed.gov., 7(1), 7-18. https://doi.org/10.1007/s10198-005-0336-8

Pope, C. A., Ezzati, M., \& Dockery, D. W. (2009). Fine-Particulate Air Pollution and Life Expectancy in the United States. The New England Journal of Medicine, 360, 376-386. https://doi.org/10.1056/NEJMsa0805646

Population and Demographic Indicators. (2016). The World Bank.

Urban population (\% of total). (2016). The World Bank Group.

Wilkinson, R. G. (1992). Income distribution and life expectancy. Bmj, 304(6820), 165-168. https://doi.org/10.1136/bmj.304.6820.165

\section{Copyright Disclaimer}

Copyright for this article is retained by the author(s), with first publication rights granted to the journal.

This is an open-access article distributed under the terms and conditions of the Creative Commons Attribution license (http://creativecommons.org/licenses/by/3.0/). 